\title{
Nanominerals assemblages and hazardous elements assessment in phosphogypsum from an abandoned phosphate fertilizer industry
}

Sabrina F. Lütke; Marcos L. S. Oliveira; Luis F. O. Silva; Tito R. S. Cadaval Jr.; Guilherme L. Dotto

\section{Abstract}

The present work investigates hazardous elements and nanomineralogical assemblages of phosphogypsum waste from an abandoned phosphate fertilizer industry located in Santa Catarina state (Brazil). Correlations between the chemical composition, nanominerals, and ultrafine particles are discussed. Multifaceted physical-geochemical study provided a careful understanding of the nanomineralogical assemblage of the phosphogypsum waste. The electron beam investigation revealed the presence of many hazardous elements in the ultrafine particles. $\mathrm{Cr}, \mathrm{Pb}$, $\mathrm{Mn}, \mathrm{Se}, \mathrm{Sr}$, and $\mathrm{Zr}$, among others, were found in individual ultrafine particles and nanominerals in all studied samples. Besides that, rare earth elements were found in different concentration ranges, being $\mathrm{Ce}, \mathrm{La}$, and $\mathrm{Nd}$, the rare earth elements, found in the higher concentrations, above $900 \mathrm{mg} \mathrm{kg}^{-1}$. The data supplied by this article are important to characterize the phosphogypsum waste, assessing the potential hazard to the environment and human health, and also, provides information to enable the designing of alternatives to manage this waste.

\section{Keywords}

Phosphogypsum; Ultrafine particles; Nanominerals; Hazardous elements 